Methods We report the case of a 28 years-old cyclist with pain in the left inguinal region and medial region of the left thigh (vas score 2 at rest), which was accentuated by external rotation movements and lateral knives (vas score 6). The clinical examination showed left adductor muscles swelling and stiffness with deep palpation pain. With the patient in the supine position and $30^{\circ}$ external rotation of the lower limb, the ultrasonography associated with elastosonography showed signs of left adductor muscle contracture (blue cromatic areas). Figure 1

Results Ultrasound-guided dry-needling was performed with a sterile seirina $\mathrm{j}$-type acupuncture needle, size $\mathrm{n}^{\circ} 8$ causing evocation of twiches of the left adductor muscles. At the end of therapy, the elastosonography re-evaluation showed signs of revascularization and major elasticity of the treated area (red cromatic areas) figure 2, there was no muscle swelling and stiffness, VAS score 0.

During the 25th-day follow-up, the patient refered muscle fatigue at the end of training, VAS score 1-2. A second dryneedling procedure was repeated, the patient reported VAS score 0 and the elastosonography showed signs of revascularization and major elasticity. Figure 3

Conclusions Our clinical and elastosonographic results, confirm that dry-needling may be an effective therapeutical option for musculoskeletal pain caused by myofascial trigger points.

\section{CLINICAL COURSE OF PATIENTS WITH LUMBAGO}

'L Molla*, ${ }^{2}$ K Preza. 'Pharmacy Gledis, Tirana, Albania; ${ }^{2}$ Continental Hospital, Tirana, Albania

\subsection{6/rapm-2021-ESRA.75}

Background and Aims The aim of this study was to assess the clinical course of patients with lumbago through 12 weeks and to identify the prognostic factors for non-recovery in the short term.

Methods A total of 74 patients with acute lumbago $(<3$ weeks) were followed up at University Hospital Centre in Tirana, Albania during the year 2019. Baseline assessments including demographic variables, clinical characteristics of pain, lost work time and results of clinical examination were noted. Pain intensity and disability, were assessed according to visual analogue scale and Roland Morris Disability Questionnaire (RMDQ), respectively. Patients were assessed for pain intensity and disability at baseline, and at 1, 2, 4, 8 and 12 weeks of follow-up. Recovery was considered if patients scored $<4$ on the RMDQ and pain had resolved. The study was approved by National Medical Ethics Committee of Albania.

Results At 2 weeks, 52 (58\%) of the patients had recovered and only eight (9\%) developed chronic LBP. Severe disability was noted among male patients (79\%) and married patients $(82 \%)$. Mean pain intensity and mean disability scores dropped 94\% and 95.2\%, respectively, of initial levels during the 12 weeks. Fifty eight percent of employed patients reported lost time from work.

Conclusions Patients with disability generally recover in the first weeks. Pain usually is the major complaint of patients with problems of the back and should be given particular consideration in baseline assessments of patients with acute lumbago.

\section{CANCER-RELATED NEUROPATHIC PAIN (CRNP): GIVING EUROPEAN PATIENTS A VOICE}

${ }^{1} \mathrm{D}$ Dupoiron*, ${ }^{2} \mathrm{~S}$ Brill, ${ }^{3} \mathrm{C}$ Eeltink, ${ }^{4} \mathrm{~B}$ Barragán, ${ }^{5} \mathrm{D}$ Bell, ${ }^{6} \mathrm{G}$ Petersen, ${ }^{7} \mathrm{~S}$ Schofield, ${ }^{8} \mathrm{M}$ Rakusa, ${ }^{9} \mathrm{D}$ Ryan. ${ }^{1}$ Institut de Cancérologie de l'ouest, Département Anesthésie Douleur, Angers Cedex 02, France; ${ }^{2}$ European Pain Federation EFIC, Brussels, Belgium ${ }^{3}$ Amsterdam UMC, Location VUmc, Department of Hematology, Amsterdam, Netherlands; ${ }^{4}$ Grupo Español de Pacientes con Cáncer (GEPAC), Madrid, Spain; ${ }^{5}$ Macmillan Cancer Support, London, UK; ${ }^{6}$ Grünenthal GmbH, Aachen, Germany; ${ }^{7}$ Grünenthal Ltd, Stokenchurch, UK; ${ }^{8}$ University Medical Centre Maribor, Department of Neurology, Maribor, Slovenia; ${ }^{9}$ Pain Alliance Europe, Brussels, Belgium

\subsection{6/rapm-2021-ESRA.76}

Background and Aims Neuropathic pain is a common longterm consequence of cancer and its treatments. A European survey has been conducted to collect insights about the diagnosis and management of CRNP and the impact on patient's lives.

Methods From February to June 2021, an online survey was conducted in 13 European countries. Adult $(18+)$ patients consenting to participate, diagnosed with cancer and experiencing neuropathic pain according to DN4 criteria and finishing the survey were included in the analyses. Survey questions were prepared together with patient representatives, clinical experts and nurses. Patients were recruited via consumer and patient online market research panels and via patient associations.

Results 549 respondents with CRNP completed the survey, thereof $62 \%$ females vs $38 \%$ males and $63 \%$ below the age of 56 years. $39 \%$ of patients had breast cancer and the remaining a variety of other cancer types. 32\% had not received a formal CRNP diagnosis, although $89 \%$ met 4 or more DN4 criteria. 32\% of respondents reported severe pain on a daily basis. 61\% responded that CRNP negatively impacts their day-to-day activities and $30 \%$ had to retire or stop working because of their CRNP. Provision of better treatments to help manage CRNP are key for $76 \%$ of patients.

Conclusions The results of this survey demonstrate that CRNP has a significant impact on the patients' daily lives. Actions need to be taken to better educate healthcare professionals about the diagnosis and treatment of CRNP and to support healthcare professional-patient communication to achieve better outcomes.

\section{SERRATUS ANTERIOR PLANE BLOCK (SAPB) FOR THE TREATMENT OF RESISTANT HERPES ZOSTER THORACIC PAIN AND NEURALGIA: DEAFFERENTATION AS AN OPTIMAL CHANCE FOR PAIN RELIEF}

${ }^{1} \mathrm{M}$ Mazzocchi ${ }^{*},{ }^{2} \mathrm{~B}$ Mascia, ${ }^{2} \mathrm{~F}$ Riccardi, ${ }^{2} \mathrm{D}$ Passador, ${ }^{2} \mathrm{M}$ Ferrari, ${ }^{2} \mathrm{G}$ Ragni, ${ }^{2} \mathrm{~F}$ Mojoli. ${ }^{1}$ Galeazzi Orthopaedic Institute, I.R.C.C.S. (Scientific Institute for Research, Hospitalization and Health Care), Milan, Italy; ${ }^{2}$ Foundation Polyclinic San Matteo, I.R.C.C.S. (Scientific Institute for Research, Hospitalization and Health (are), Pavia, Italy

\subsection{6/rapm-2021-ESRA.77}

Background and Aims Herpes Zoster reactivation causes inflammatory and hemorrhagic reaction in the posterior roots of spinal nerves and sensitive ganglia. Postherpetic neuralgia $(\mathrm{PHN})^{1}$ is a neuropathic pain that occurs in $25 \%$ of patients older than $50^{2,3}$. Pharmacological therapy is often uneffective; intrathecal steroid injections and nerve blocks may be tried $^{4}$. 